\title{
Prevalence of Dental Anomalies in Deciduous Teeth and their Correlation with the Permanent Dentition: Double Teeth, Hypodontia and Hyperdontia
}

\author{
Vaska Vandevska-Radunovic ${ }^{1 *}$, Maneva Marija² and Zuzelova Marija² \\ ${ }^{1}$ Department of Orthodontics, Institute for Clinical Odontology, University of Oslo, Norway \\ ${ }^{2}$ Department of Orthodontics, Faculty of Dentistry, Saints Cyril and Methodius University of Skopje, Skopje, Republic of North Macedonia
}

*Corresponding author: Vaska Vandevska-Radunovic, Professor, Head of section, Department of Orthodontics, Institute for Clinical Odontology, University of Oslo, Geitmyrsveien 69/71, 0455, Oslo, Norway, E-mail: vaska.vandevska-radunovich@odont.uio.no

Received: 12 Apr, 2019 | Accepted: 30 Apr, 2019 | Published: 06 May, 2019

Citation: Vandevska-Radunovic V, Marija M, Marija Z (2019) Prevalence of Dental Anomalies in Deciduous Teeth and their Correlation with the Permanent Dentition: Double Teeth, Hypodontia and Hyperdontia. Int J Dent Oral Health 5(4): dx.doi.org/10.16966/2378-7090.292

Copyright: (C) 2019 Vandevska-Radunovic V, et al. This is an open-access article distributed under the terms of the Creative Commons Attribution License, which permits unrestricted use, distribution, and reproduction in any medium, provided the original author and source are credited.

\begin{abstract}
Context: Dental anomalies of number, shape and size can easily compromise the development and function of the dentition, since normal tooth morphology is one of the factors contributing to a well-balanced and stable occlusion.

Aims: The aim of this study was to investigate the prevalence of dental anomalies in the primary dentition and their influence on the development of the dental anomalies in the permanent dentition.

Materials and Methods: The sample consisted of 2350 children, 1300 girls and 1050 boys, aged 4-6 years, attending public kindergartens in the central city area of Skopje. The examination was conducted as a part of the Project for Mental and Body Health of the city of Skopje in the Centre for Mental Health of the Republic of North Macedonia. Dental anomalies in number and morphology were registered as follows: double teeth, hypodontia and hyperdontia. A panoramic radiograph was taken of those children that demonstrated one or more of these anomalies in order to evaluate the status of the permanent dentition.

Results and Conclusions: Twenty-one children (0.89\%) had anomaly of the primary teeth. Hyperdontia was most prevalent (0.38\%), while hypodontia was the least prevalent anomaly $(0.21 \%)$. Seven children had double teeth $(0.30 \%)$. Except for hypodontia, the anomalies were more prevalent in girls, but the difference was not significant. There was a high correlation coefficient between the dental anomalies in the deciduous and permanent dentition $(r=0.8)$. This indicates the need for early monitoring of the permanent dentition and occlusion in children with primary dental anomalies.
\end{abstract}

Keywords: Dental anomalies; Primary dentition; Hypodontia; Hyperdontia; Double teeth

\section{Introduction}

Dental anomalies of number, shape and size can easily compromise the development and function of the dentition, since normal tooth morphology is one of the factors contributing to a well-balanced and stable occlusion. Epidemiological investigations show that the prevalence of dental anomalies in the primary dentition is rare but variable, depending on the type of anomaly, gender and population [1-5].

Hyperdontia is the least prevalent dental anomaly in the primary dentition, ranging from $0.05 \%-0.6 \%[3,6,7]$. Although it is increasing, the lowest prevalence is registered in Japanese children, and this is significantly less than the prevalence of supernumerary primary teeth in Caucasian and Chinese populations [2-5]. In contrast, congenitally missing primary teeth (hypodontia) are more often found amongst Asians, and the prevalence ranges from $0.1-4.1 \%$ [4-8]. The formation of double teeth (fusion and germination), is the only dental anomaly that is more common in the deciduous than in the permanent dentition. Its prevalence is highly variable, from $0.7 \%$ to $4.1 \%[2,8]$ and is more common in boys than in girls $[2,5]$.

The majority of the cases with dental anomalies in the primary dentition do not require comprehensive treatment. However, these anomalies often indicate a pending treatment problem in the future, as $50-70 \%$ are associated with anomalies in the permanent dentition $[1,8]$. Eruption disturbances, crowding or spacing are some of the problems that may be encountered, often requiring an interdisciplinary treatment approach [9]. Therefore, early recognition of deciduous tooth anomalies may lead to early diagnosis and long-term treatment planning of dento-alveolar anomalies in the permanent occlusion.

The aim of this study was to investigate the prevalence of dental anomalies in the primary dentition and their influence on the 
development of the dental anomalies in the permanent dentition. Similar investigations have never been conducted on a Macedonian population. Taking into consideration that anomalies of number and size are population and gender dependent, it was of interest to compare the results from this study with those from previous investigations on different populations.

\section{Materials and Methods}

The sample consisted of 2350 children, 1300 girls and 1050 boys, aged 4-6 years, attending public kindergartens in the central city area of Skopje. All children showing up for the dental check-up were included in the study. The examination was conducted as a part of the Project for Mental and Body Health of the city of Skopje in the Centre for Mental Health of the Republic of North Macedonia. The project, including the dental check-up, was initiated and organized by the health authorities. Therefore, no specific ethical approval was needed. Information and a letter of invitation were sent to all included kindergartens. The children were examined during a period of approximately 6 months (September 2015-March 2016) in the local dental clinic. Two experienced orthodontists (MM, MZ) did the extra-oral inspection and intraoral dental check-up, using a dental mirror and a probe under standard dental light. The check-ups were done simultaneously, but individually. In cases of uncertainty, both orthodontists investigated the child and an agreement was reached. Dental anomalies in number and morphology were registered as follows: 1) double teeth: including both fusion and germination according to Carvalho, et al. [10]. 2) Hypodontia: absence of teeth and 3) Hyperdontia: increased number of teeth. Fusion of teeth is union in dentin and/or enamel between teeth and an incomplete division of a tooth germ is germination. Clinically, without a periapical radiograph, a differential diagnosis would be difficult. Therefore, the term "double teeth" was used. A panoramic radiograph was taken of those children that demonstrated one or more of these anomalies in order to evaluate the status of the permanent dentition. These radiographs were taken approximately 1-2 years after the clinical examination. The orthodontists jointly evaluated the dental anomalies on the panoramic radiographs.

In patients with missing deciduous teeth, a careful examination was carried out in order to determine the reason for the absence of the tooth: congenital or acquired. If necessary, parents were questioned about the possible reasons, in order to exclude causes such as extraction due to caries, trauma or early exfoliation.

Percentages, Chi-square test and correlation coefficient were used to analyses data and test gender differences. Gender differences were tested with Chi-square test and the level of significance was set at $\leq$ 0.05. (SPSS, 20.0.0; SPSS Inc, Chicago, IL, USA).

\section{Results}

Of the 2350 examined children 1050 (44.7\%) were boys and 1300 (45.3\%) were girls. A total of 21 children, $(0.89 \%)$, had anomalies of the primary teeth (Table 1). Hyperdontia was the most prevalent anomaly, which was registered in nine children, while hypodontia was the least prevalent anomaly with only five children missing a primary tooth (Table 1). Seven children had double teeth (fusion and germination). Except for hypodontia, the anomalies were more prevalent in girls than in boys, but the difference was not significant $(\mathrm{p} \geq 0.05)$.

The investigation of the panoramic radiographs revealed that 13 $(61.9 \%)$ of the 21 children with anomalies in the deciduous dentition had anomalies in the permanent dentition (Table 2). Out of seven patients with double teeth, two demonstrated the same anomaly in the
Table 1: Distribution of dental anomalies (double teeth, hypodontia and hyperdontia) in the deciduous dentition of preschool children in the city of Skopje.

\begin{tabular}{|l|c|c|c|c|c|c|}
\hline & \multicolumn{2}{|c|}{$\begin{array}{c}\text { Girls } \\
(\mathrm{n}=1300)\end{array}$} & \multicolumn{2}{c|}{ Boys $(\mathrm{n}=1050)$} & \multicolumn{2}{c|}{ Total $(\mathrm{n}=2350)$} \\
\hline Dental anomaly & $\mathrm{n}$ & $\%$ & $\mathrm{n}$ & $\%$ & $\mathrm{n}$ & $\%$ \\
\hline Double teeth & 5 & 0.38 & 2 & 0.19 & 7 & 0.3 \\
\hline Hypodontia & 2 & 0.15 & 3 & 0.29 & 5 & 0.21 \\
\hline Hyperdontia & 5 & 0.38 & 4 & 0.38 & 9 & 0.38 \\
\hline Total & 12 & 0.92 & 9 & 0.86 & 21 & 0.89 \\
\hline
\end{tabular}

Table 2: Distribution of dental anomalies in the deciduous and permanent dentition of the same individual; one tooth per person.

\begin{tabular}{|l|c|c|}
\hline \multicolumn{1}{|c|}{ Dental anomaly } & Deciduous dentition & Permanent dentition \\
\hline Double teeth & 7 & 2 \\
\hline Hypodontia & 5 & 5 \\
\hline Hyperdontia & 9 & 6 \\
\hline Total & 21 & 13 \\
\hline
\end{tabular}

permanent dentition; only one tooth was affected. All children who had hypodontia of deciduous teeth had hypodontia of permanent teeth as well. From the nine children with hyperdontia, only six had the anomaly in the permanent dentition.

There was a high correlation coefficient between the dental anomalies in the deciduous and permanent dentition $(r=0.8)$. The most affected tooth was the maxillary lateral incisor, observed in 18 of 21 deciduous teeth and nine of 13 permanent teeth. The other affected teeth were in the mandibular anterior segment (Table 3).

\section{Discussion and Conclusion}

The results of the present cross-sectional epidemiological study show low prevalence of dental anomalies like double teeth, hypodontia and hyperdontia in the primary dentition of a Macedonian population, with no significant gender differences. The latter is similar to the findings reported in most of the previous studies [5,7,11,12], although some investigations show boys having significantly more dental anomalies than girls $[2,13]$.

The overall distribution of all anomalies was less than $1 \%$ and it seems to be lower than the percentage reported in similar studies (Table 4). Direct comparison might be difficult, but ethnic differences and possible underscoring cannot be ruled out. However, considering the total population and the number of 4-6 year-old-ones in the country, the sample of children investigated in this study is high and encompasses approximately $4 \%$ of all $4-6$ year old children [14]. Thus, it is representative and reliable, as it is much higher than those coming from the most populous countries $[2,4,5,7]$.

Fusion and germination are difficult to be distinguished clinically, particularly in investigations of large samples. Therefore, to avoid incorrect diagnosis, we used "double teeth" for both anomalies; a term that has been used in other studies for the same reason $[10,13]$. The results showed that only seven children had double teeth, which is $0.30 \%$ of the population. This is slightly lower, but in concordance with other studies in Caucasians, which show prevalence of double teeth less than $1 \%[5,7,10,12]$. The anomaly is much more prevalent in Asian populations, where $3 \%$ to $4.1 \%$ of the children are reported to 
Table 3: Teeth with dental anomalies in the deciduous dentition and corresponding teeth with anomalies in the permanent dentition.

\begin{tabular}{|c|c|c|}
\hline Dental anomaly & Deciduous dentition & Permanent dentition \\
\hline & \multicolumn{2}{|c|}{ Teeth involved (number of teeth) } \\
\hline \multirow{2}{*}{ Double teeth } & Maxillary lateral incisor (6) & \multirow{2}{*}{ Maxillary lateral incisor (2) } \\
\hline & Mandibular central incisor (1) & \\
\hline \multirow{2}{*}{ Hypodontia } & Maxillary lateral incisor (4) & Maxillary lateral incisor (4) \\
\hline & Mandibular central incisor (1) & Mandibular central incisor (1) \\
\hline \multirow{2}{*}{ Hyperdontia } & Maxillary lateral incisor (8) & Maxillary lateral incisor (3) \\
\hline & Mandibular lateral incisor (1) & Mesiodens (3) \\
\hline
\end{tabular}

Table 4: Prevalence of dental anomalies in deciduous dentitions of different population groups.

\begin{tabular}{|l|c|c|c|c|}
\hline \multicolumn{1}{|c|}{ Authors } & Country & Sample size & Hyperdontia \% & Hypodontia \% \\
\hline Ravn (1971) & Denmark & 4564 & 0.6 & 0.6 \\
\hline Whittington (1996) & New Zealand & 1680 & 0.18 & 0.36 \\
\hline Yonezu (1997) & Japan & 2733 & 0.07 & 2.38 \\
\hline King (2007) & China & 936 & 2.8 & 4.1 \\
\hline Chen (2010) & Taiwan & 2611 & $<1$ & 2 \\
\hline Kapdan (2012) & Turkey & 1149 & 0.3 & 0.2 \\
\hline Gomes (2014) & Brazil & 1718 & 0.29 & 0.29 \\
\hline Shilpa (2017) & India & 4180 & 0.21 & 0.38 \\
\hline Present study & North Macedonia & 2350 & 0.38 & 0.21 \\
\hline
\end{tabular}

have double teeth, indicating racial and ethnical differences $[2,4,15]$. Heredity may also be involved, considering the fact that siblings tend to have the same anomaly [16].

Hypodontia in primary teeth is also shown to be more prevalent in Asian populations compared to Caucasians [2,17]. An overview of selected studies (Table 3 ) demonstrates prevalence of $<1 \%$ among Caucasians and between 2-4.1\% among Asians. This difference may be attributed to genetic factors, but despite the strong genetic control of tooth development, the etiology of hypodontia is most probably multifactorial [18]. The affected teeth are usually mandibular central incisors and maxillary lateral incisors, with different prevalence in various samples. Some report higher prevalence in the mandible [2,15], others show no difference between the jaws $[5,19]$. The prevalence in our sample was very low; only five children had hypodontia $(0.21 \%)$ and rather similar jaw distribution.

The dental anomaly with highest prevalence in the present sample was hyperdontia: nine children $(0.38 \%)$ demonstrated supernumerary deciduous teeth. Despite having the highest prevalence in this study, it is rather low and is similar to most of the reported studies $[2,7,11,13]$. This is not surprising, as, like hypodontia, hyperdontia is much less frequent in the primary than in the permanent dentition [20]. It has been stated that visual inspection can underestimate the number of supernumerary teeth, and additional radiographs can show unerupted supernumeraries which are not registered clinically. In the present study, it is very unlikely that the prevalence of hyperdontia would have increased by using radiographs, since most of the children were in their late primary dentition.

Dental anomalies in the primary dentition do not present a great risk for the child's oral health and function and they are not treated. However, they can give an indication of the dental and occlusal problems a child can encounter in the permanent dentition. Almost all studies that investigate the prevalence of dental anomalies in the primary dentition show positive correlation with associated anomalies in the permanent dentition $[8,11,12,21]$. The results from the present investigation confirm these claims. All children with hypodontia of deciduous teeth had hypodontia of permanent teeth, and more than half of the patients with hyperdontia in the primary dentition demonstrated supernumerary teeth in the permanent dentition. Most of the children with double teeth had normal permanent dentition; only two out of seven exhibited changes that indicated supernumerary teeth. It has been mentioned that children with "double" primary teeth, might have other anomalies in the permanent dentition, including hypodontia, hyperdontia, double or malformed teeth, and/ or sometimes delayed eruption. Regardless the specific abnormality, it is well advised that children with primary dental anomalies be closely monitored for associated anomalies in the permanent dentition. Since anomalies are most often located in the anterior region, they can lead to esthetic impairment, but also complicate an already existing malocclusion [22,23]. It has also been shown that dental anomalies in the permanent dentition are significantly associated with each other [24]. Therefore, early diagnosis can enable appropriate and timely treatment planning, and interceptive treatment, thus preventing possible complications and extensive orthodontic treatment.

The present investigation was carried out in a limited city district and did not include rural regions. No photographs were taken during the clinical examination and inter-and intra-investigator reliability could not be ascertained. Furthermore, dental anomalies in the permanent dentition might have been overestimated in cases where permanent tooth germs developed later than the taken radiograph. On the other hand, dental anomalies could have developed in the children without anomalies in the primary dentition. These shortcomings might have 
influenced the results and the conclusions have to be considered within the limits of these drawbacks.

It can be concluded that the overall prevalence of dental anomalies in the primary dentition of the present sample is low and similar to other Caucasian populations. Hyperdontia was most prevalent, while hypodontia was the least prevalent anomaly. The high correlation between primary dental anomalies and anomalies in the permanent dentition is of clinical importance and suggests the need for early monitoring of the permanent dentition in these cases.

\section{Conflicts of Interest}

No conflicts of interest are reported.

\section{References}

1. Nik-Hussein NN, Abdul Majid Z (1996) Dental anomalies in the primary dentition: distribution and correlation with the permanent dentition. J Clin Pediatr Dent 21: 15-19.

2. Yonezu T, Hayashi Y, Sasaki J, Machida Y (1997) Prevalence of congenital dental anomalies of the deciduous dentition in Japanese children. Bull Tokyo Dent Coll 38: 27-32.

3. Miyoshi S, Tanaka S, Kunimatsu H, Murakami $Y$, Fukami M, et al. (2000) An epidemiological study of supernumerary primary teeth in Japanese children: a review of racial differences in the prevalence. Oral Dis 6: 99-102.

4. King NM, Tongkoom S, Itthagarun A, Wong HM, Lee CK (2008) A catalogue of anomalies and traits of the primary dentition of Southern Chinese. J Clin Pediatr Dent 32: 139-146.

5. Kramer PF, Feldens CA, Ferreira SH, Spiguel MH, Feldens EG (2008) Dental anomalies and associated factors in 2-to5-year-old Brazilian children. Int J Paediatr Dent 18: 434-440.

6. Koch G, Thesleff I, Kreiborg S (2009) Tooth development and disturbances in number and shape of teeth. In: Koch G,Poulsen S, Espelid I, Haubek D (eds) Pediatric Dentistry. A Clinical Approach. $3^{\text {rd }}$ edition, Oxford: Wiley.

7. Shilpa G, Gokhale N, Mallineni SK, Nuvvula S (2017) Prevalence of dental anomalies in deciduous dentition and its association with succedaneous dentition: A cross-sectional study of 4180 South Indian children. J Indian Soc Pedod Prev Dent 35: 56-62.

8. Whittington BR, Durward CS (1996) Survey of anomalies in primary teeth and their correlation with the permanent dentition. $\mathrm{N} Z$ Dent J 92: 4-8.

9. Tuna EB, Yildirim M, Seymen F, Gencay K, Ozgen M (2009) Fused teeth: a review of the treatment options. J Dent Child (Chic) 76: 109116.
10. Carvalho JC, Vinker F, Declerck D (1998) Malocclusion, dental injuries and dental anomalies in the primary dentition of Belgian children. Int J Paediatr Dent 8: 137-141.

11. Gomes RR, Fonseca JAC, Paula LM, Acevedo AC, Mestrinho HD (2014) Dental anomalies in primary dentition and their corresponding permanent teeth. Clin Oral Invest 18: 1361-1367.

12. Aydinbelge $M$, Sekerci $A E$, Caliskan $S$, Gumus $H$, Sisman $Y$, et al. (2017) Clinical and radiographic evaluation of double teeth in primary dentition and associated anomalies in the permanent successors. Niger J Clin Pract 20: 847-851.

13. Kapdan A, Kustarci A, Buldur B, Arslan D, Kapdan A (2012) Dental anomalies in the primary dentition of Turkish children. Eur J Dent 6: $178-183$.

14. Natality in the Republic of Macedonia, 2017.

15. Chen YH, Cheng NC, Wang YB, Yang CY (2010) Prevalence of congenital dental anomalies in the primary dentition in Taiwan. Pediatr Dent 32: 525-529.

16. Aguiló L, Gandia JL, Cibrian R, catala M (1999) Primary double teeth. A retrospective clinical study of their morphological characteristics and associated anomalies. Int J Ped Dent 9: 175-183.

17. Niswander JD, Sujaku C (1963) Congenital anomalies of teeth in Japanese children. Am J Phys Anthropol 21: 569-574.

18. Brook AH (2009) Multilevel complex interactions between genetic, epigenetic and environmental factors in the etiology of anomalies of the dental development. Arch Oral Biol 54: S3-S17.

19. Ravn JJ (1971) Aplasia, supernumerary teeth and fused teeth in the primary dentition. An epidemiologic study. Scand J Dent Res 79: 1-6.

20. Dash JK, Sahoo PK, Das S, Mohanty UK (2003) Prevalence of supernumerary teeth in deciduous and mixed dentition. J Ind Soc Pedod Prev Dent 21: 37-41.

21. Mukhopadhyay S, Mitra S (2014) Anomalies in primary dentition: Their distribution and correlation with permanent dentition. J Nat Sc Biol Med 5: 139-143.

22. Haugland L, Storesund T, Vandevska-Radunovic V (2013) Prevalence of dental anomalies in Norwegian school children. Open J Stomatol 3: 329-333.

23. Roslan AA, Rahman NA, Alam MK (2018) Dental anomalies and their treatment modalities/planning in orthodontic patients. J Orthod Sci 7: 16 .

24. Laganà G, Venza N, Borzabadi-Farahani F, Danesi C, Cozza P (2017) Dental anomalies: prevalence and associations between them in a large sample of non-orthodontic subjects, a cross-sectional study. BMC and Oral Health 17: 62. 